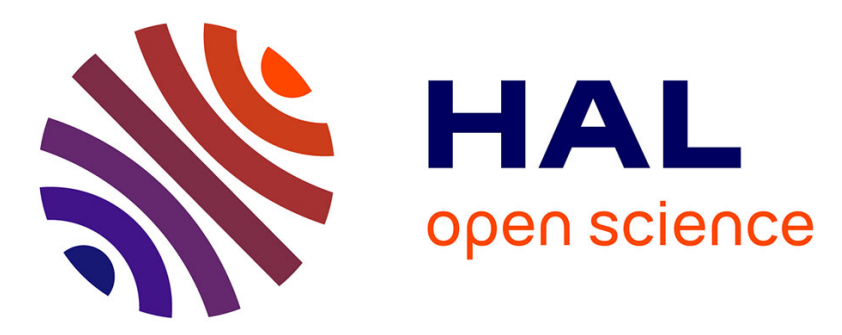

\title{
The Effect of Diamagnetic Defect in YIG on the Hyperfine Field Anisotropy
}

J. Kohout, H. Stepankova, J. Englich, P. Novak, H. Lütgemeier

\section{To cite this version:}

J. Kohout, H. Stepankova, J. Englich, P. Novak, H. Lütgemeier. The Effect of Diamagnetic Defect in YIG on the Hyperfine Field Anisotropy. Journal de Physique IV Proceedings, 1997, 07 (C1), pp.C1-449-C1-450. 10.1051/jp4:19971182 . jpa-00254831

\section{HAL Id: jpa-00254831 https://hal.science/jpa-00254831}

Submitted on 1 Jan 1997

HAL is a multi-disciplinary open access archive for the deposit and dissemination of scientific research documents, whether they are published or not. The documents may come from teaching and research institutions in France or abroad, or from public or private research centers.
L'archive ouverte pluridisciplinaire HAL, est destinée au dépôt et à la diffusion de documents scientifiques de niveau recherche, publiés ou non, émanant des établissements d'enseignement et de recherche français ou étrangers, des laboratoires publics ou privés. 


\title{
The Effect of Diamagnetic Defect in YIG on the Hyperfine Field Anisotropy
}

\author{
J. Kohout, H. Stepankova, J. Englich, P. Novak* and H. Lütgemeier**
}

\author{
Faculty of Mathematics and Physics, Charles University, V Holesovickach 2, 18000 Prague 8, Czech \\ Republic \\ * Institute of Physics, Academy of Sciences, Cukrovarnicka 10, 16000 Prague 6, Czech Republic \\ **IFF, KFA Jülich, 52425, Germany
}

\begin{abstract}
The dependence of ${ }^{57} \mathrm{Fe}$ NMR spectra in YIG on the external magnetic field direction was measured at $4.2 \mathrm{~K}$. The high purity single crystal of a spherical form was used. The external magnetic field of $0.75 \mathrm{~T}$ was applied in several directions lying in (110) plane. The satellite structure of the spectra caused by an antisite defects $\mathrm{Y}(a)\left(\mathrm{Y}^{3+}\right.$ ion on the $a$ site, nominally occupied by $\mathrm{Fe}^{3+}$ ion) enabled us to study the effect of a nonmagnetic impurity on the ${ }^{57} \mathrm{Fe}$ hyperfine field anisotropy. The tensors of hyperfine interaction for ${ }^{57} \mathrm{Fe}$ in $d$ - sites with the nearest and next nearest $\mathrm{Y}$ (a) defect were obtained from NMR data. The results were confronted with the predictions of the independent bond model.
\end{abstract}

In magnetic oxides, the crystal environment influences the hyperfine field on the nuclei of $\mathrm{Fe}^{3+}$ ions mainly via the effect of covalence and the effect of electron supertransfer in the $\mathrm{Fe}^{3+}-\mathrm{O}^{2-}-\mathrm{Fe}^{3+}$ triad [1]. If $\mathrm{Fe}^{3+}$ ion is substituted by a diamagnetic cation, the hyperfine fields on iron nuclei in its vicinity are modified by the change of supertransfer (and of dipolar field) contribution from this site. As the value of the hyperfine field determines the NMR frequency, the effect of the supertransfer can be studied by analyzing the ${ }^{57} \mathrm{Fe} \mathrm{NMR}$ spectra of samples containing a diamagnetic impurity on the iron sites. Such spectra include main lines of ${ }^{57} \mathrm{Fe}$ nuclei in sites without any diamagnetic substitution in their vicinity, and weaker satellite lines corresponding to various relative positions of the resonating ${ }^{37} \mathrm{Fe}$ nuclei and the nearby impurity. The frequency shift between the satellite and the corresponding main line has an isotropic and an anisotropic (dependent on the direction of magnetization) parts. While the isotropic part (after subtracting of the dipolar field component) is associated with the s-electrons, the anisotropic part reflects the changes in the occupation of 3d-electron states and therefore is closely related to the exchange interaction [2].

This work presents results of the complete analysis of the hyperfine field anisotropy in $d$ sites of yttrium iron garnet (YIG). In an ideal YIG $\left(\mathrm{Y}_{3} \mathrm{Fe}_{5} \mathrm{O}_{12}\right) \mathrm{Fe}^{3+}$ ions occupy fully $d$ (tetrahedral) and $a$ (octahedral) positions, while $\mathrm{Y}^{3+}$ enters $c$ (dodecahedral) sites. In real YIG crystals, the yttrium antisite defects $\mathrm{Y}(a)$, i.e. $\mathrm{Y}^{3+}$ replacing $\mathrm{Fe}^{3+}$ in $a$ sites, induce satellite lines in the NMR spectrum. Two sets of satellites (marked $d_{1}$ and $d_{2}$ ) are observed in addition to the $d$ main line (see Fig.1). The $d_{1}$ and $d_{2}$ sets have been assigned to the configuration in which the $\mathrm{Y}(a)$ defect is the nearest and second nearest $a$ site neighbour of the resonating ${ }^{57} \mathrm{Fe}$ nuclei on the $d$ site, respectively [3]. Any $d$ site has four nearest and four second nearest $a$ site neighbours. Taking into account 12 different local orientations of $d$ sites in the crystal structure, each set of satellite lines corresponds to a NMR signal from 12x4=48 crystallographically equivalent configurations. As a consequence of the hyperfine field anisotropy, frequencies of main and satellite lines depend on the magnetization direction.

To determine this anisotropy, ${ }^{57} \mathrm{Fe}$ NMR spectra of the high purity YIG single crystal prepared from the $\mathrm{BaO} / \mathrm{B}_{2} \mathrm{O}_{3}$ flux were studied in an external magnetic field. The measurements were carried out at $4.2 \mathrm{~K}$ by spin echo technique using the conventional coherent pulse NMR spectrometer with Fourier transform. To avoid differences in demagnetization field, a spherical sample was used. An external field of $0.75 \mathrm{~T}$, high enough to turn the magnetization, was applied in six different directions lying in the (110) crystallographic plane.

The angular dependence of the resonance frequencies corresponding to a specific set of crystallographically equivalent configurations can be described by

$$
\mathbf{f}^{\mathbf{c}}(\mathbf{n})=\mathbf{I}+\mathbf{n}\left(\mathbf{G}^{-}\right)^{-1} \mathbf{A} \mathbf{G}^{\mathbf{c}} \mathbf{n},
$$

where $\mathbf{n}=\left(\mathrm{n}_{\mathrm{x}}, \mathrm{n}_{\mathrm{y}}, \mathrm{n}_{\mathrm{z}}\right)$ is the magnetization direction. I and $\mathbf{A}$ are the isotropic part and the second order tensor, respectively, characterizing the hyperfine field behavior. $\mathbf{A}$ is a symmetrical tensor $\left(A_{i j}=A_{j i}\right)$ with zero trace. The symbol $c$ is an index of individual configuration and $G^{c}$ the vector representation of the point-symmetry operation, which creates configuration $c$ from the reference configuration $(\mathrm{c}=1)$.

For the $\mathrm{Fe}^{3+}$ ions in $d$ sites unperturbed by the defect (the $d$ main line) $\mathbf{A}$ is invariant with respect to the $d$ site symmetry ( $\mathrm{S}_{4}^{(2)}$ ). This condition implies axial symmetry of the $\mathbf{A}$ (i.e. $\mathrm{A}_{x y}=\mathrm{A}_{\mathrm{xz}}=\mathrm{A}_{\mathrm{yz}}=0 ; \mathrm{A}_{\mathrm{xx}}=\mathrm{A}_{\mathrm{yy}}$ ). The set of differently oriented $d$ sites (c=1,...,12) is created by symmetry operations of point-symmetry subgroup $T$. Due to the axial symmetry of $A, 3$ different $f^{c}$ are obtained for the 
magnetization in a general direction (4 sites contributing to each line). In the zero external field the magnetization is parallel to the 3-fold rotation axis $\langle 111\rangle$ and all the 3 lines coincide (see Fig.1, top spectrum). For the magnetization in the (110) plane two lines with the intensity ratio $2: 1$ are predicted and really observed (Fig.1., bottom spectrum).

Presence of an $Y(a)$ in the vicinity of the $d$ site (satellites $d_{1}$ or $d_{2}$ ), destroys the local site symmetry. Tensor $A$ then has 5 independent components. Both sets of crystallographically equivalent configurations $(c=1, \ldots, 48)$ are created by the symmetry operations of the complete crystal point-symmetry group $\left(\mathrm{O}_{\mathrm{h}}\right)$. Because expression $(1)$ is invariant with respect to the inversion, maximum number of different satellite lines in the set is $48 / 2=24$. In zero external field (magnetization in (111) direction) the number of different frequencies is reduced to 4 , while for magnetization in the (110) plane 12 different frequencies are expected. For $d_{1}$ satellites an additional coincidence of two frequencies was observed, reducing the number of different satellites to 3 and 11 lines, respectively. This is connected with two off-diagonal A components being approximately equal.

The measured dependence of resonant frequencies on the direction of the external field in the (110) plane (given by the angle $\vartheta$ from $\langle 001\rangle$ ) was fitted using formula (1) (see Fig.2). The values of the isotropic term and of all A components were determined by the fit for the main line (marked $\left.d_{0}\right)$ and the two sets of satellites $\left(d_{1}, d_{2}\right)$ and are given below in MHz:
$\mathrm{L}_{\mathrm{d} 0}=64.961$
$\mathrm{I}_{\mathrm{dl}}=64.231$
$\mathrm{I}_{\mathrm{d} 2}=65.223$
$A_{d 0}=\left(\begin{array}{lll}0.046 & 0 & 0 \\ 0 & 0.046 & 0 \\ 0 & 0 & -0.092\end{array}\right)$
$\mathbf{A}_{\mathrm{d} 1}=\left(\begin{array}{rrr}0.227 & 0.271 & -0.244 \\ 0.271 & -0.241 & 0.272 \\ -0.244 & 0.272 & 0.015\end{array}\right)$
$\mathbf{A}_{\mathrm{d} 2}=\left(\begin{array}{lll}0.006 & 0.014 & 0.060 \\ 0.014 & -0.058 & 0.045 \\ 0.060 & 0.045 & 0.054\end{array}\right)$

Although the fitted dependencies follow experimental results excellently (see Fig.2), small systematic deviations, at the level comparable with experimental error, were still detected. They originate in the higher order terms, neglected in (1). We estimated that these terms, namely those containing the fourth order anisotropy tensor, cause the shift of satellite frequencies by several $\mathrm{kHz}$, only.

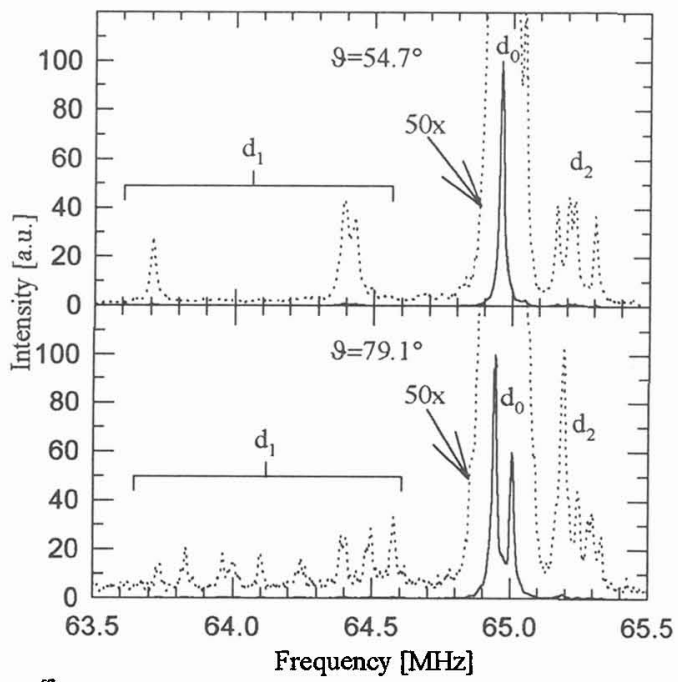

Fig. $1{ }^{57} \mathrm{Fe}$ NMR spectra of $d$ sites at $4.2 \mathrm{~K}$. (a) zero extemal field (b) external field $0.75 \mathrm{~T}$ in one of the used directions in $(110)$ plane given by the angle $\&$ from $\langle 001\rangle$ (shift caused by the external and the demagnetization field was compensated by corresponding shift of the frequency scale).

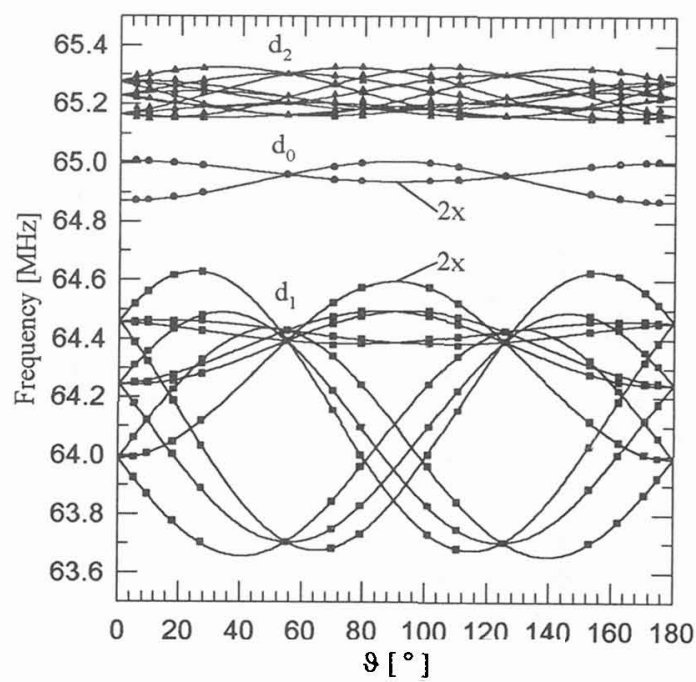

Fig. 2 The dependence of ${ }^{5 x} \mathrm{Fe}$ NMK trequencies in $a$ siles on une magnetization direction in (110) plane (experimental points and fitted curves).

The $\mathbf{A}_{\mathrm{dl}}$ tensor obtained above may be used to check the validity of the 'superposition' (or 'independent' bond) model of the hyperfine field [4]. This model predicts that (after subtracting the effect of dipolar field) the angular dependence of the satellite line is given by a square of the cosine of an angle which the magnetization makes with the $\mathrm{Fe}^{3+}-\mathrm{O}^{\prime}$ bond. Here $\mathrm{O}^{\prime}$ denotes the oxygen ligand in the triad $\mathrm{Fe}^{3+}-\mathrm{O}^{\prime}-\mathrm{Y}(a)$ defect. This simple dependence was compared with the one obtained using the $\mathbf{A}_{\mathrm{dl}}$ tensor. No reasonable agreement has been found, however. This indicates that the 'superposition model' is not a good approximation for the situation studied here (resonating nuclei on the $d$ site, defect on the nearest $a$ site).

\section{References}

[1] van der Woude F., G.A.Sawatzky G.A., Phys. Rev.B 4 (1971) 3159-3165.

[2] Tomás D., Novák P., Stěpánková H., J. Magn, Magn. Mater. 140-144 (1995) 2133-2134

[3] Novák P.,Englich J.,Stěpánková H.,Kohout J.,Lütgemeier H., Wagner K., Tolksdorf W., Phys.Rev.Lett. 75 (1995) $545-548$

[4] Englich J., Brabenec M., Novák P., Lütgemeier H., J. Magn. Magn. Mater. 50 (1985) 74-82 